This article was downloaded by: [University of Alberta]

On: 26 April 2015, At: 14:36

Publisher: Routledge

Informa Ltd Registered in England and Wales Registered Number: 1072954

Registered office: Mortimer House, 37-41 Mortimer Street, London W1T

3J H, UK

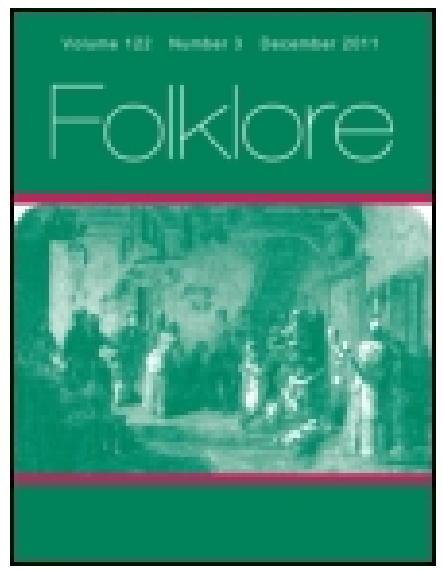

\title{
Folklore
}

Publication details, including instructions for authors and subscription information:

http:// www. tandfonline.com/loi/ rfol20

\section{Supplementary Notes on Cat's Cradle and String-Tricks}

W. Innes Pocock

Published online: 14 Feb 2012.

To cite this article: W. Innes Pocock (1907) Supplementary Notes on Cat's Cradle and String-Tricks, Folklore, 18:3, 325-329, DOI: 10.1080/ 0015587X.1907.9719782

To link to this article: http:// dx. doi. org/ 10.1080/0015587X.1907.9719782

\section{PLEASE SCROLL DOWN FOR ARTICLE}

Taylor \& Francis makes every effort to ensure the accuracy of all the information (the "Content") contained in the publications on our platform. However, Taylor \& Francis, our agents, and our licensors make no representations or warranties whatsoever as to the accuracy, completeness, or suitability for any purpose of the Content. Any opinions and views expressed in this publication are the opinions and views of the authors, and are not the views of or endorsed by Taylor \& Francis. The accuracy of the Content should not be relied upon and should be independently verified with primary sources of information. Taylor and Francis shall not be liable for any losses, actions, claims, proceedings, demands, costs, expenses, damages, and other liabilities whatsoever or howsoever caused arising directly or indirectly in connection with, in relation to or arising out of the use of the Content.

This article may be used for research, teaching, and private study purposes. Any substantial or systematic reproduction, redistribution, reselling, loan, sub-licensing, systematic supply, or distribution in any form to anyone is 
expressly forbidden. Terms $\&$ Conditions of access and use can be found at http://www.tandfonline.com/page/terms-and-conditions 
eldest brother of her late husband claims her by the law of inheritance, and takes her away to his own village and home. She and all her children become his property. He enters into all the rights of the real husband. Before the brother can claim the widow he must make her an offering of tobacco, after which he goes to her hut, taking with him several friends and male relatives. When they reach the house, one of these relatives enters the hut, and, as he steps over the threshold, he stamps several times with his feet, and calls out to the deceased husband, "Thou hast no longer possession of this hut; I come to claim it all." The widow, who is sitting on a hide in the ground, now unties her tobacco, gives a little to each one present, and, after mead or milk has been drunk, the ceremony is over.

It is unusual for Gallas to sell their relations, but under exceptional circumstances a man has sold his brother's widow and sometimes her female children. Galla parents inculcate very emphatically the virtue of chastity upon their daughters, and when a case of shame occurs amongst them it is deeply mourned over as a sad disgrace. Formerly, maidens guilty of a breach of purity were thrown into the Sabaki River and drowned.

E. S. WAKEFIELD.

\section{Supplementary Notes on Cat's Cradle and STRING-TRICKS.}

I AM indebted to Dr. Haddon for permission to publish the following Rumanian string-tricks, which he obtained last year from Mr. L. Gaster. The descriptions are from Dr. Haddon's notes.

The generic name (represented in English by the misapplied word "Cat's" cradle) is given as "Etelbetel."

I. Put one end of the loop over the head. Bring the right string across between the teeth. Do the same with the left string. Cross the strings back again. Pass the long front loop over the head and pull the hands apart.

2. Hang the loop over the left thumb and index. With the 
right index pull out the string between the left thumb and index to form a long loop. Bring the right hand back above the left hand and close the left thumb and index, inclosing all strings. Insert the closed left thumb and index proximally in the right index loop, drawing the right hand away and the string runs out (Fig. A).

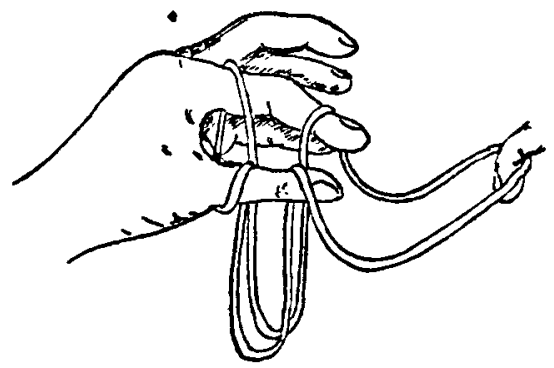

FIG. A.

In the diagram the left thumb and index have been separated again after passing for the last time through the loop. This facilitates the final movement.

3. Put the loop over the left little finger and interlace the strings in and out through the fingers, crossing them between each finger and the next, but always keeping the palmar little finger string proximal. Loop round the thumb and return, keeping the string mentioned distal and its initial movement round the back of the index. Release the thumb, pull the slack of the loop from the ulnar side, and the string runs out.

4. Pass the loop through the buttonhole and hold the ends on the thumbs. Catch the ulnar string of the left thumb with the right little finger, and moving the left little finger clear above the loop so made catch with it the right thumb radial string. Release the thumb of one hand and the little finger of the other. Extend and the string runs out.

The first of these tricks is the same as that which in FolkLore for September, 1906 (vol. xvii. p. 356) I have called "Cutting off the head." My knowledge of that trick was derived when a young child from a still younger child who had seen it and gave me a partial description, which I supplied by the only 
conjecture I was capable of. My description must thus have been subject to grave suspicion, and it is satisfactory to have it confirmed from this unexpected quarter.

When I compared this trick with that obtained by Dr. Cunnington from the Yao of the Shire highlands (No. 2, Cunnington, in J.A.I., vol. xxxvi., Jan.-June, I906), I had not seen Mr. Dudley Kidd's description of the Basutoland string-trick quoted by Dr. Haddon in the same number of the journal. The latter, as far as I understand it, seems to me to be practically the same as this Rumanian example. It may be noticed that there is a kind of elementary juggling in both which distinguishes them from the Yao trick, in which the effect depends entirely on the properties of a loop of string.

No. 2 is another application of the Watch-Guard hitch. I imagine it to be a simple form of the Hand string-trick of which I gave two descriptions (vol. xvii., pp. 367,368 ). The essential movements are identical, but as the Rumanian trick has no move corresponding to that by which both strings are passed round the thumb in the English trick, attention is diverted by closing the thumb and finger, which thus represents the ring fixed to a wall or immovable block. If the ring thus made by the fingers be considered to be a watch handle the whole person represents the watch; and a somewhat ludicrous reversion of the trick may be made with a sufficiently long loop, thus :-Give the right index loop to another person to hold; close the finger and thumb above both strings, and offer to free the fixed end of the loop which lies on the palmar aspect of the thumb and index. This may be done by pulling down the palmar string, stepping through that end of the loop and passing it up over the head. It will then pull clear.

No. 3 is the same as the trick which, following Dr. Weir, I have called the Mouse Alternative. It is the variety credited to Miss Hingston in my article (vol. xvii., pp. 369, 370).

No. 4 is an interesting variety of the Button-hole trick (p. 353). I should guess it to be a more primitive form than the one I have described. The latter is characterised by a sleight-ofhand-a feature which, as far as I recollect, it shares with only two other tricks-the well-known "Threading-the-needle" and 
the trick I have called the "Mended Ends." One or two others, perhaps, like the Basuto trick referred to above, evince an inclination towards legerdemain.

It seems proper here to mention that during a tour in the low countries in the fall of 1905 , I saw what may have represented a European form of another East African trick published by Dr. Cunnington (J.A.I., vol. xxxvi., Jan.-June, 1906 : Trick No. 18 of the Ubwari, Lake Tanganyika). I was testing the knowledge of Cat's Cradle possessed by some children at Tilburg, South Brabant, and one of them attempted to show me a process which began with extending the string on the wrists, and, after a manoeuvre with the side string, ended by laying hold of the string behind one of the wrists and whipping it clear. As I did not know the trick and the little girl could not do it, we got no further. It is easy, however, to present the Ubwari trick in a simpler form by giving a half-turn to the radial side string and inserting both hands in this fresh loop, keeping the straight string still on that side. The string can then be freed from the back of one or other wrist, but not both. It might be worth looking out for this trick in England or on the Continent. It is of a kind that might be expected to have a wide distribution.

Since my notes on Cat's Cradle appeared in Folk-Lore in March, 1906 (vol. xvii., p. 73), I have obtained one or two additional names for some of the figures.

A young lady at Haarlem who played Cat's Cradle just as I learnt it (that is, without the Korean or "Scraggly" "figures), ${ }^{1}$ called the first position "de Brug," or the bridge, and "Fish-in-theDish," "Het Varken op de Lêer," or the pig on the ladder, i.e. the pig hung up in the butcher's shop. ${ }^{2}$

II afterwards got the "Scraggly" figure from a Rotterdam man employed at a hotel at Medemblik in North Holland.

"I have seen the "ladder" in question in butchers' shops at Clifton, viz. two parallel rails about eighteen inches apart, united by straight rungs at intervals ; but on enquiry I cannot find the name "ladder" applied to it. One butcher at Cambridge whom I interrogated had heard it, but considered it strange and thought the speaker might be a foreigner. Other Cambridge butchers gave the name " rail " to the rectangular system of three or four rods, generally duplicated, which run round the ceiling of the shop, supporting hooks for carcases. 
A schoolboy at Portishead, East Somerset, calls Cat's Cradle, "The Hammock." He plays the ordinary sequence as far as the Fish figure, which he declares is the Hammock, the previous figures being steps thereto. He could give no further account of the game nor say how he learnt it, except that an epidemic of it (so to speak) had broken out at the school some time previously. His mother, who came from a distant village also in East Somerset, knew the game, but not by the same name: she thought it was called the Chair, or something like that, but could not speak decidedly.

It seems to me possible that the Fish figure may really be the original objective. When compared by the standard of the Oceanic and American string-games, the figures which precede it seem scarcely to merit more than the name of positions, while the final is a figure in the most exacting sense of the word.

W. InNes Pocock.

\section{Folk-Medicine, NURSery-Lore, etc., from the EgeAN ISLANDS.}

RABIES in a dog is caused by its eating a green bird brought by the wind.

Storks' eggs are good for ophthalmia.

For a sore, squeeze a live frog and put it on the sore.

For headache, cut open a live hen and put it on the head.

For the consequences of sudden fright, eat the heart of a live pigeon (still beating), with sugar.

"Agriopetalida" is pounded up and burnt. The ashes are an emmenagogue, and are also used for varicose veins.

"The Virgin's tears" (gum found in certain trees) protects from the bite of scorpions and of the samiomitis, a small lizard which is supposed to bite, but does not as a fact.

Agnus-castus leaves and tamarisk leaves are good for headache. 